\title{
Physicochemical, Rheological, \& Sensory Characteristics of Yogurt Fortified with Ball- Milled Roasted Chickpea Powder (Cicer arietinum L.)
}

\author{
Husnain RAZA ${ }^{1,2,3 *}$ (D), Kashif AMEER ${ }^{4,5}$, Farah ZAABOUL ${ }^{2,3}$, Muhammad SHOAIB ${ }^{2,3}$, Chang-Cheng ZHAO ${ }^{6}$, \\ Barkat ALI ${ }^{2,3}$, Muhammad Talha SHAHZAD ${ }^{7}$, Muhammad ABID ${ }^{8}$, Xiaofeng REN ${ }^{1}$, Lianfu ZHANG ${ }^{2,3,9,10 \star ~}$
}

\begin{abstract}
This study was aimed at evaluation of effects of ball-milled roasted chickpea (RC) powder on physicochemical, rheological and sensorial properties of yogurt supplemented with RC levels of 1 (RCY1), 2 (RCY2), 3 (RCY3), 4 (RCY4), and 5 g/100 $\mathrm{mL}$ (RCY5). Results showed a gradual decline in the $\mathrm{pH}$ of pre-inoculated samples with corresponding increases in powder concentration from 1 to $5 \mathrm{~g} / 100 \mathrm{~mL}$. Degrees of lightness and yellowness increased in supplemented samples as compared to control (RCY0). Higher firmness was exhibited by RCY3 and RCY5 samples in the range of 59.39-78.56 g. RCY3 showed the highest consistency value $(1480.214 \mathrm{~g} / \mathrm{s})$. Overall, the syneresis was significantly lower $(p<0.05)$ in supplemented samples as compared to control. The addition levels of more than 3\% RC resulted in smoother and more gradual dispersive patterns of particles, and RCY4 showed the most prominent polydispersity and resembled RCY5. Comparatively, supplemented samples exhibited a significantly lower degree of shear-thinning as compared to control samples. RCY5 showed the maximum texture score among all supplemented samples, and supplemented samples showed comparable sensory attributes to those of control samples. It was evident from this study that RC powder can be employed as a functional food ingredient in yogurt production.
\end{abstract}

Keywords: chickpea; yogurt; physicochemical; rheology; sensory; texture.

Practical Application: Chickpea-fortified yogurt can be used as a valuable source of essential nutrients for various consumer groups.

\section{Introduction}

Since the last decade, the consumer demand for functional foods with health-promoting properties manufactured from natural ingredients has increased rapidly (Sarkar, 2019). Yogurt is usually perceived as an important functional food owing to its therapeutic and nutritional significance (Öztürk et al., 2018). As a dairy product, yogurt preparation usually involves fermentation aided by starter cultures comprising of Lactobacillus delbrueckii subsp. Bulgaricus and Streptococcus thermophilus. Yogurt fortification or supplementation with phenolic-rich foods is one of the most widely employed techniques to impart improved antioxidant, physicochemical and sensory characteristics of fermented milk products (Amerinasab et al., 2015; Sah et al., 2016). Unfortunately, the majority of the probiotic bacteria do not exhibit rapid growth in milk. Therefore, a large number of studies have been carried out during the last years, which aimed to investigate the effects of supplementation on milk enrichment for growth promotion of probiotics for improved well-being
(Zare et al., 2012). In this regard, several supplementation strategies involving the addition of polyphenol-rich fruits, extracts, vegetable powders, and pulps as a flavoring, such as citrus, ginseng, soybean, yeast, peanut, tomato, cereals, honey, mangoes, berries, herbs, whey protein concentrate and isolates (Öztürk et al., 2018; Sah et al., 2016) have been reported as non-traditional additives in the production of fermented dairy products with improved probiotic properties. Moreover, reduction of syneresis through the addition of non-milk additives, such as chickpea the addition of guar gum, mucilage, hydrocolloids like gelatine and fiber-rich fruit peel powder and oleaster flour have also been suggested to improve physiochemical, textural and sensory qualities of yogurt (Öztürk et al., 2018).

Apart from the promotion of probiotic bacteria, supplementation of food products, including yogurt, may lead to improve nutritional, sensorial, and physicochemical properties

Received 03 Nov., 2020

Accepted 10 Dec., 2020

${ }^{1}$ School of Food and Biological Engineering, Jiangsu University, Zhenjiang, Jiangsu, P.R. China

${ }^{2}$ State key Laboratory of Food Science and Technology, Jiangnan University, Wuxi, Jiangsu, China

${ }^{3}$ School of Food Science and Technology, Jiangnan University, Wuxi, Jiangsu, China

${ }^{4}$ Department of Integrative Food, Bioscience and Biotechnology, Chonnam National University, Gwangju, South Korea

${ }^{5}$ School of Food Science and Biotechnology, Kyungpook National University, Daegu, South Korea

${ }^{6}$ School of Life Sciences, Zhengzhou University, Zhengzhou, Henan, China.

${ }^{7}$ School of Science, RMIT University, Melbourne, Victoria, Australia

${ }^{8}$ Institute of Food and Nutritional Sciences, PMAS-Arid Agriculture University, Rawalpindi, Pakistan

${ }^{9}$ Beijing Advanced Innovation Center for Food Nutrition and Human Health, Beijing Technology and Business University, Beijing, China

${ }^{10}$ Collobrative Innovation Center for Food Safety and Quality Control in Jiangsu Province, Jiangnan University, Wuxi, Jiangsu, China

*Corresponding author: husnain_ju@hotmail.com; lianfu@jiangnan.edu.cn 
(Bosnea et al., 2017). In this regard, food products were fortified extensively in the past to incorporate garlic (Arslaner, 2020), lutein as a functional ingredient (Barros et al., 2020), pine honey (Coskun \& Karabulut Dirican, 2019), cereals or fruit-derived fiber, milk-derived protein isolates, concentrates, and whey proteins (Paseephol et al., 2008; Zare et al., 2011) as well as symbiotic yogurt (Ribeiro et al., 2019). However, very few reports have reported on yogurt fortification through pulses-derived ingredients. Pulses and legumes as low-caloric foods provide valuable nutrients like bioactive compounds, minerals, dietary fiber, polyphenols, vitamins, carotenoids, and antioxidants with minimum amounts of unsaturated fats. Legislation pertaining to yogurt fermentation ensures compliance to have total solids up to $2 \%$, which provides a chance for improvement of healthpromoting and quality properties of yogurt (Sah et al., 2016).

Consequently, novel functional dairy products may be developed by supplementing yogurt with legumes for enhancing health-promoting properties. In recent years, the food industry has focused its interest on leguminous crops and utilization of the legumes owing to the high protein contents and strong dietary recommendation of legumes by scientists and nutritionists worldwide (Soltani et al., 2018). Moreover, ball-milling has replaced traditional milling owing to particle size reduction benefits and the provision of fine powders without exerting any damage on the physicochemical properties of foods (Ramadhan \& Foster, 2018). Among legumes, chickpea (Cicer arietinum L.) is popular among conscious consumers and is used around the globe in the form of roasted snack products (Raza et al., 2019; Zhong et al., 2018). Ingredients from pulses, including roasted chickpea (RC), may serve as excellent sources of prebiotic and growth factors for supplementation of yogurt and probiotic beverages with improved physicochemical, rheological, and sensory characteristics (Raza et al., 2019; Zare et al., 2011). To the best of our knowledge, no report is available in the published literature on supplementation and quality improvement of yogurt with ball-milled chickpea flour. Therefore, in this study, RC powder was used for yogurt supplementation, and the effects of ball-milled RC powder on yogurt physiochemical, rheological, and sensorial properties were investigated.

\section{Materials and methods}

\subsection{Raw materials}

Chickpeas were provided by Xinjiang Tian Shan Qi Dou Biotechnology Co. Ltd. The sample was collected from a single lot $(20 \mathrm{~kg})$ and stored at room temperature $\left(25 \pm 2{ }^{\circ} \mathrm{C}\right)$ in PET containers prior to use.

\subsection{Chickpea roasting}

Chickpeas were roasted with pilot-scale short-wave infrared roaster: (Senttech Infrared Technology Co., Ltd, Taizhou, China) at $180^{\circ} \mathrm{C}$ for $25 \mathrm{~min}$.

\subsection{Ball-milling}

The roasted chickpeas were ground using a ball miller followed by micronization with a planetary ball mill (PM 100,
Retsch, Germany). In this mill, the samples were mixed with $10 \mathrm{~mm}$ zirconia balls (volume ratio 1:1) in a $250 \mathrm{~mL}$ grinding jar and milled for $5 \mathrm{~min}$ at a rotary speed of $400 \mathrm{rpm}$ for $4 \mathrm{~h}$ with the interval of $15 \mathrm{~min}$ to avoid overheating of the powder. The milled sample was then passed through a standard sieve 200 mesh (<75 um).

\subsection{Yogurt preparation}

Roasted chickpea powder (RC) was added to the commercial UHT milk at 1, 2, 3, 4, and $5 \mathrm{~g} / 100 \mathrm{~mL}$ (RCY1, RCY2, RCY3, RCY4, and RCY5), then the mixtures were heated at $55^{\circ} \mathrm{C}$ for 80-90 min with constant agitation to dissolve the powder in milk. These were then homogenized at $300 \mathrm{mPa}$ to uniformly dissolve the roasted chickpea powder in milk, followed by pasteurization at $85^{\circ} \mathrm{C}$ for $10 \mathrm{~min}$. Finally, the solutions were cooled down to $42^{\circ} \mathrm{C}$ and inoculated with $0.1 \mathrm{~g} / 100 \mathrm{~mL}$ starter cultures, and then incubated in 6 beakers $(250 \mathrm{~mL})$ for $6 \mathrm{~h}$ at $43^{\circ} \mathrm{C}$. After incubation, the yogurt was cooled down to $10^{\circ} \mathrm{C}$ stored at $4{ }^{\circ} \mathrm{C}$ until the next day for analysis.

\section{$2.5 \mathrm{pH}$ measurements}

The $\mathrm{pH}$ values of yogurt samples during storage were measured using a digital $\mathrm{pH}$ meter (Mettler Toledo, Shanghai, China) at room temperature. Yogurt samples were stirred well before measurement.

\subsection{Color analysis}

The color of yogurt samples was determined with a ColorQuest $t^{\circ}$ X.E. spectrophotometer (Hunter Associates Laboratory Inc., Reston, Virginia, USA), which was standardized using a white reference tile through EasyMatch ${ }^{\bullet}$ Q.C. software. The yogurt samples $(\sim 20 \mathrm{~mL})$ were put into an optically-clear glass cell with a fixed path length of $10 \mathrm{~mm}$, with dimensions of measurement face $(55 \times 57 \mathrm{~mm})$. Glass cell was placed on the shelf with light cover at the reflectance port with the large area viewport plate (1-inch) installed. A lens is located at an angle of $8^{\circ}$ from the perpendicular to the sample surface. The results were expressed as $L^{*}$ (lightness; $100=$ white, $0=$ black), $a^{*}$ (red-green; positive values $=$ red, negative values $=$ green $)$, and $b^{*}$ (yellow-blue; positive values $=$ yellow, negative values $=$ blue) values. Every sample was read in triplicate.

\subsection{Texture analysis}

Yogurt texture was evaluated by the backward-extrusion test using the TA-XT plus texture analyzer (Texture Technologies Corp, New York, USA) equipped with a $5 \mathrm{~kg}$ loading cell. The parameters were modified from the template in exponent: cylinder probe of $35 \mathrm{~mm}$ diameter, test speed $1.0 \mathrm{~mm} / \mathrm{s}$, penetration distance $30 \mathrm{~mm}$, and surface trigger force $10 \mathrm{~g}$. The tests were carried out on the samples prepared in $125 \mathrm{~mL}$ Nalgene (Thermo Scientific, Canada) containers of $64 \mathrm{~mm}$ diameter and $70 \mathrm{~mm}$ height. Firmness $(\mathrm{N})$, consistency $\left(\mathrm{N}^{*} \mathrm{~s}\right)$, cohesiveness $(\mathrm{N})$, and viscosity index $\left(\mathrm{N}^{\star} \mathrm{s}\right)$ were calculated using the Exponent program. 


\subsection{Syneresis and water holding capacity (WHC)}

Syneresis and WHC were determined according to the previously-reported method with minor modifications. Yogurt samples were centrifuged (Eppendorf Centrifuge $5804 \mathrm{R}$, Hamburg, Germany) at $4{ }^{\circ} \mathrm{C}$ and at $2800 \times \mathrm{g}$ for $5 \mathrm{~min}$. The clear supernatant was poured off and weighed. Syneresis and WHC were calculated by using the formats (1) and (2), respectively, as follows:

Syneresis $(g / 10 g)=W / Y * 10$

$W H C(\%)=Y-W / Y * 100$

Where $\mathrm{W}$ was the whey expelled, and $\mathrm{Y}$ was the sample weight. All determinations were performed in triplicate.

\subsection{Rheological analysis}

The shear viscosity tests were performed using a rotational rheometer (CVO 50, Bohlin Rheometer; Malvern Instruments Ltd., Malvern, UK) with a cone and plate measuring system at $25 \pm 0.1 \_$. The shear viscosity tests were performed under the controlled rate mode. The shear rate range was $0.1-100 / \mathrm{s}$. For each experimental run, the set type yogurt sample was used prior to the shear viscosity tests. Measurements were performed in triplicate.

The dynamic viscoelastic properties of the yogurt samples were measured on the CVO 50 rheometer with the cone and plate measuring system at $25 \pm 0.1^{\circ} \mathrm{C}$. The amplitude sweep tests were performed at $0.1 \mathrm{~Hz}, 1 \mathrm{~Hz}$, and $10 \mathrm{~Hz}$ to identify the linear viscoelastic range for the yogurt samples. The amplitude sweep tests were performed under the controlled stress mode in the range of 0.03-100 Pa. The frequency sweep tests were performed in the frequency range of $0.1-10 \mathrm{~Hz}$ under constant stress.

\subsection{Sensory evaluation}

Sensory evaluation was based on the recognition of the relative importance of selected quality attributes, including color, texture, aroma, and taste. The rating was assigned separately for each parameter on a 0 to 9 descriptive hedonic scale ( 9 being the highest score for associated attributes, 1 was the lowest and 0 not exist, a score of 5 was taken as the average score for minimum sensory acceptability). All panelists were selected based on availability, preparedness to participate, and prior experience on trained panels. Eight panelists were included to perform the sensory evaluations. The panelists were provided with instructions on how to perform the sensory profiling of the yogurt samples. The sample presentation order was randomized for each panelist. Samples were presented to the panelists in plastic-covered coded containers $(80 \mathrm{~mL})$. Water cups were provided between samples to cleanse the palate. The panelists were carried out during storage periods in three replications.

\subsection{Statistical analysis}

All experiments were repeated in triplicate, and data were demonstrated as mean \pm standard deviation (S.D.) of triplicate measurements. The results were subjected to statistical analysis using the SAS program (ver. 6.04, SAS, Cary, NC), and differences between the means were compared by Duncan multiple range test at the significance level of $p<0.05$.

\section{Results and discussion}

\subsection{Effect on pH of supplemented yogurt during storage}

The $\mathrm{pH}$ results of yogurt samples added with roasted chickpea powder and control samples are given in Table 1 . Prior to inoculation at $0 \mathrm{~h}$, the control (RCY0) showed a $\mathrm{pH}$ of 6.6, whereas yogurt samples added with chickpea powders showed $\mathrm{pH}$ in the range of 6.19-6.62. It was revealed that the addition of chickpea powder caused a gradual decline in $\mathrm{pH}$ values of pre-inoculated samples with corresponding increases in powder concentration from 1 to $5 \mathrm{~g} / 100 \mathrm{~mL}$. However, the RCY5 sample showed $\mathrm{pH}$ values similar to $\mathrm{RCY}$, which revealed that the addition of roasted chickpea powder did not cause any significant change in the $\mathrm{pH}$ of yogurt samples as compared to control. $\mathrm{pH}$ values of yogurt samples were again analyzed after $6 \mathrm{~h}$ of inoculation. The $\mathrm{pH}$ values of supplemented yogurt samples ranged from 4.62-4.74 in comparison with control samples (RCY0: $\mathrm{pH}$ 4.71). Overall, the addition of starter culture led to a significant decline in $\mathrm{pH}$ values, which indicated the usual occurrence of the fermentation process caused by the starter culture. The addition of chickpea powder caused a decline in $\mathrm{pH}$ values in a consistent manner, and the RCY5 yogurt sample showed $\mathrm{pH}$ values similar to that was found for RCY0. After one week of storage, the $\mathrm{pH}$ values showed further decreases, and $\mathrm{pH}$ values of supplemented samples were found in the range of 4.44-4.56. RCY5 showed a pH value similar to RCY0. These results revealed that the addition of roasted chickpea powders did not cause any

Table 1. Water holding capacity (WHC), syneresis and $\mathrm{pH}$ values of roasted chickpea yogurts before and after incubation for 6 hours and during storage at $4 \pm 1{ }^{\circ} \mathrm{C}$ for 7 days.

\begin{tabular}{cccccc}
\hline Sample & Synersis $(\mathrm{g} / 10 \mathrm{~g})$ & WHC $(\%)$ & \multicolumn{2}{c}{$\mathrm{pH}$} \\
\cline { 3 - 6 } & & & $0 \mathrm{~h}$ & $6 \mathrm{~h}$ & $1 \mathrm{w}$ \\
\hline RCY0 & $2.45 \pm 0.19 \mathrm{a}$ & $75.55 \pm 1.88 \mathrm{a}$ & $6.60 \pm 0.01 \mathrm{a}$ & $4.71 \pm 0.06 \mathrm{a}$ & $4.55 \pm 0.07 \mathrm{a}$ \\
RCY1 & $2.84 \pm 0.17 \mathrm{ab}$ & $71.60 \pm 1.70 \mathrm{~b}$ & $6.43 \pm 0.03 \mathrm{a}$ & $4.62 \pm 0.04 \mathrm{a}$ & $4.47 \pm 0.03 \mathrm{a}$ \\
RCY2 & $2.73 \pm 0.04 \mathrm{abc}$ & $72.72 \pm 0.44 \mathrm{bc}$ & $6.32 \pm 0.03 \mathrm{~b}$ & $4.66 \pm 0.07 \mathrm{a}$ & $4.46 \pm 0.00 \mathrm{a}$ \\
RCY3 & $2.19 \pm 0.09 \mathrm{bc}$ & $78.13 \pm 0.94 \mathrm{bcd}$ & $6.26 \pm 0.06 \mathrm{bc}$ & $4.62 \pm 0.04 \mathrm{a}$ & $4.44 \pm 0.04 \mathrm{a}$ \\
RCY4 & $2.29 \pm 0.02 \mathrm{c}$ & $77.09 \pm 0.16 \mathrm{~cd}$ & $6.19 \pm 0.04 \mathrm{c}$ & $4.67 \pm 0.04 \mathrm{a}$ & $4.45 \pm 0.00 \mathrm{a}$ \\
RCY5 & $1.12 \pm 0.05 \mathrm{~d}$ & $88.80 \pm 0.54 \mathrm{~d}$ & $6.62 \pm 0.06 \mathrm{c}$ & $4.74 \pm 0.06 \mathrm{a}$ & $4.56 \pm 0.04 \mathrm{a}$ \\
\hline
\end{tabular}

Means \pm standard deviation (S.D) in the same column with different alphabet letters indicate the significant difference at $p<0.05$. 
undesirable $\mathrm{pH}$ changes as a function of incubation time during acidification of the yogurt products supplemented with roasted chickpea powder, which can lead to a detrimental effect on the quality properties of yogurt. The decreasing tendency of $\mathrm{pH}$ after $6 \mathrm{~h}$ and 7 days of inoculation showed that yogurt samples' buffering capacity influenced the fermentation process. These results are in agreement with the findings of Zare et al. (2012), who also reported that supplementation of yogurt by pulses did not cause any significant change in $\mathrm{pH}$ values as compared to control (normal) yogurt samples.

\subsection{Effect on color values of supplemented yogurt}

The effects of supplementation on yogurt color values were analyzed with the addition of roasted chickpea powder, and results are presented in Table 2. $L^{*}$-values denote the degree of lightness, and results showed that the addition of roasted chickpea powder led to slight increases in the lightness of manufactured yogurt products (RCY1-RCY5) as compared to control, and $L^{*}$-values increasing tendency showed a linear relationship with corresponding increases of roasted chickpea powder which can be attributed to the presence of fiber, proteins, and starches in inherent compositions of ball-milled roasted chickpea powder. In Hunter's color scale, $a^{*}$-values represent the changes in degrees of redness and greenness. The control samples (RCY0) showed $a^{*}$-value of -0.83 , which implied the presence of green tinge in control samples; however, the $a^{*}$-values showed increases in a gradual and consistent manner with corresponding rises of additional levels of roasted chickpea powder. The highest $a^{*}$ values were shown by RCY 5 samples (1.08), which implied that the degree of redness was increased owing to increases in total solids in manufactured yogurts and slight tinges of red color were clearly evident from the positive a-values in comparison with control (RCY0) samples. On the other hand, $b^{*}$-values give an indication about degrees of yellowness $\left(+b^{*}\right.$-values) and blueness (- $b^{*}$-values). The $b^{*}$-value of the control sample was 11.57, whereas the supplemented yogurt samples showed $b^{*}$ values in the range of $12.45-14.08$. The level-dependent increases in $b^{*}$-values of supplemented yogurts showed that roasted chickpea powder led to an increasing tendency of yellowness, which can be attributed to the presence of starches, proteins, and other complex components in the inherent compositional profile of chickpea powder. It was shown that chickpea powders did not cause any significant change in color properties, which may hamper the appearance and organoleptic characteristics and improved the color properties of prepared yogurts. Similar results were reported by (Staffolo et al., 2004), who also reported no influence of the addition of dietary fiber from wheat, apple, bamboo, and inulin on yogurt color during the extended storage period of 25 days.

\subsection{Effect on textural parameters of set-type supplemented yogurt}

All yogurt samples were analyzed for changes in textural attributes after subjecting to one day of storage, and results are presented in Table 2. In the case of textural attributes, firmness, consistency, cohesiveness, and force of cohesion were measured for all control and supplemented yogurt samples. Firmness shows significant increases by increasing the addition levels of roasted chickpea powder. The initial addition levels of 1 and $2 \mathrm{~g} / 100 \mathrm{~mL}$ in RCY 1 and RCY2, respectively, led to a gradual rise in firmness, whereas further rises in roasted chickpea powder resulted in significantly higher firmness levels in RCY3 and RCY5 samples in the range of 59.39-78.56 g. The firmness of control (RCY0) samples was $55.84 \mathrm{~g}$. This implied that roasted chickpea powder exerted significant $(p<0.05)$ influence on the firmness of supplemented yogurt products. This could be attributed to the fact of reinforcement phenomenon pertaining to the gel structure. Roasted chickpea resulted in the formation of microcrystals, which intacted the molecular network in supplemented yogurt owing to the absorption of adequate water, which produced fine texture by mimicking characteristics of milk fat, and this effect was more prominent in RCY 3 and RCY5 samples. In the case of yogurt consistency, RCY3 showed the highest consistency value $(1480.21 \mathrm{~g} / \mathrm{s})$ whereas, all other supplemented yogurt samples showed a slight improvement in yogurt consistency in the range of $1182.31-1331.24 \mathrm{~g} / \mathrm{sec}$ as compared to that observed for control samples $(1256.87 \mathrm{~g} / \mathrm{s})$. The addition of roasted chickpea powder exhibited a positive influence on the cohesiveness of supplemented yogurt samples, and RCY2 showed the highest cohesiveness among all samples, whereas the cohesiveness of control samples was relatively lower. Similarly, the work of cohesion also showed significant improvement because the addition of roasted chickpea powder and the RCY3 samples showed the highest values as compared to control. Similar results were reported by (Paseephol et al., 2008), where inulin addition led to improvements in textural and rheological properties of yogurts in comparison with non-supplemented control samples.

Table 2. Effect of roasted chickpeas powder addition on the color and textural parameters of yogurt

\begin{tabular}{|c|c|c|c|c|c|}
\hline \multirow{2}{*}{ Sample } & \multirow{2}{*}{$\begin{array}{c}\text { Color } \\
\mathrm{L}^{*} \\
\end{array}$} & \multirow{2}{*}{$a^{*}$} & \multirow{2}{*}{$b^{*}$} & \multicolumn{2}{|c|}{ Textural parameters } \\
\hline & & & & Firmness & Consistency \\
\hline RCY0 & $95.45 \pm 0.00 \mathrm{a}$ & $-0.83 \pm 0.01 f$ & $11.57 \pm 0.02 \mathrm{f}$ & $55.84 \pm 0.48 \mathrm{~d}$ & $1256.87 \pm 28.44 \mathrm{bc}$ \\
\hline RCY1 & $94.54 \pm 0.00 \mathrm{~b}$ & $0.00 \pm 0.01 \mathrm{e}$ & $12.45 \pm 0.01 \mathrm{e}$ & $59.15 \pm 0.68 c$ & $1309.93 \pm 11.58 b$ \\
\hline RCY2 & $93.51 \pm 0.01 \mathrm{c}$ & $0.48 \pm 0.00 \mathrm{~d}$ & $12.52 \pm 0.01 \mathrm{~d}$ & $59.39 \pm 0.54 c$ & $1182.31 \pm 19.84 c$ \\
\hline RCY3 & $92.41 \pm 0.01 \mathrm{~d}$ & $0.94 \pm 0.01 \mathrm{c}$ & $13.42 \pm 0.02 c$ & $79.03 \pm 0.27 \mathrm{a}$ & $1480.24 \pm 14.44 a$ \\
\hline RCY4 & $92.26 \pm 0.01 \mathrm{e}$ & $0.98 \pm 0.01 b$ & $13.54 \pm 0.02 b$ & $76.30 \pm 0.38 b$ & $1330.79 \pm 21.86 b$ \\
\hline
\end{tabular}

Means \pm standard deviation (S.D) in the same column with different alphabet letters indicate the significant difference at $p<0.05$. 


\subsection{Changes in syneresis and WHC of supplemented yogurt}

Supplemented and non-supplemented yogurt samples were analyzed for their syneresis and WHC, and results are tabulated in Table 1. Synersis provides the measurement of released serum or whey from yogurt samples. Syneresis has been reported as an undesirable characteristic of yogurt products and serves as a measure to evaluate the quality of yogurt products. Syneresis showed a decreasing tendency in supplemented yogurts with corresponding rises in added levels of roasted chickpea powder. Overall, the syneresis was significantly higher $(p<0.05)$ in control samples as compared to supplemented samples. Moreover, it was suggested by one previous study that serum released from the yogurt gel structure was absorbed by the dietary fiber. The decreasing tendency of syneresis in supplemented yogurt might be a consequence of increased WHC of chickpea powder (Öztürk et al., 2018). The highest syneresis was observed in RCY1 (2.84 g/10 g), whereas RCY5 showed the lowest degree of syneresis $(1.12 \mathrm{~g} / 10 \mathrm{~g})$. Similar results were reported by (Barkallah et al., 2017), whereby high dietary fiber content from spirulina led to a significant reduction in syneresis in fortified yogurt samples in comparison with control. Moreover, decreasing the tendency of syneresis corresponds to a reduction in serum release of whey, which in turn contributes to improve the water retention capacity with an increase in the denaturation of proteins. As syneresis and WHC are interrelated to each other in an inverse manner, therefore, supplemented samples with addition levels of roasted chickpea powder up to 1 an $2 \%$ showed lower WHC values whereas RCY3, RCY 4 and RCY 5 showed significantly higher WHC as compared to control and WHC increasing tendency was gradual. Highest WHC (88.80\%) was shown by RCY5, whereas RCY1 showed the lowest WHC of $71.60 \%$. As increases in WHC are directly related to retention of higher protein content and higher protein content in roasted chickpea powder could be possibly ascribed to be the reason for corresponding rises in WHC with an increase in total solids and protein content of supplemented yogurts. Similar results have been reported in previously published reports whereby higher WHC has been recorded owing to reduced synersis because of higher fiber, protein and total solids content (Jridi et al., 2015; Barkallah et al., 2017; Kermiche et al., 2018).

\subsection{Particle size distribution (PSD) of roasted chickpea powder dispersed in skim milk before incubation}

The results of the PSD analysis are shown in Figure 1. The number of bins or channels in the output indicates the resolution of the instrument. The size bins may be wide or narrow, depending on the resolution of the data (Figure 1a). The results revealed that control and RCY1 and RCY2 demonstrated similar polydispersity patterns with no apparent differences in their distributions cures (Figure 1b). Further rises in roasted chickpea powder caused variations in dispersive patterns of particles in supplemented yogurt samples, and RCY3 samples showed marked variations in polydispersity as compared to RCY4 and RCY5 samples. The addition levels of more than 3\% resulted in smoother and more gradual dispersive patterns of particles, and RCY4 showed the most prominent polydispersity and also resembled with dispersive patterns of RCY5. Both RCY4 and RCY 5 showed relatively broader PSD curves, which can be possible due to the coalescing phenomenon due to increased starch and protein contents found in ball-milled derived roasted chickpea powders (Figure 1b). An increasing tendency in addition levels of roasted chickpea powder caused the massive formation of a densely-packed interconnected network of chickpea protein with casein micelles (Ciron et al., 2010). In correspondence with these results, similar findings have been reported by Wang et al. (2020), who concluded that homogenization affected the monodispersive PSD curves of yogurts owing to the formation of densely packed casein protein networks.
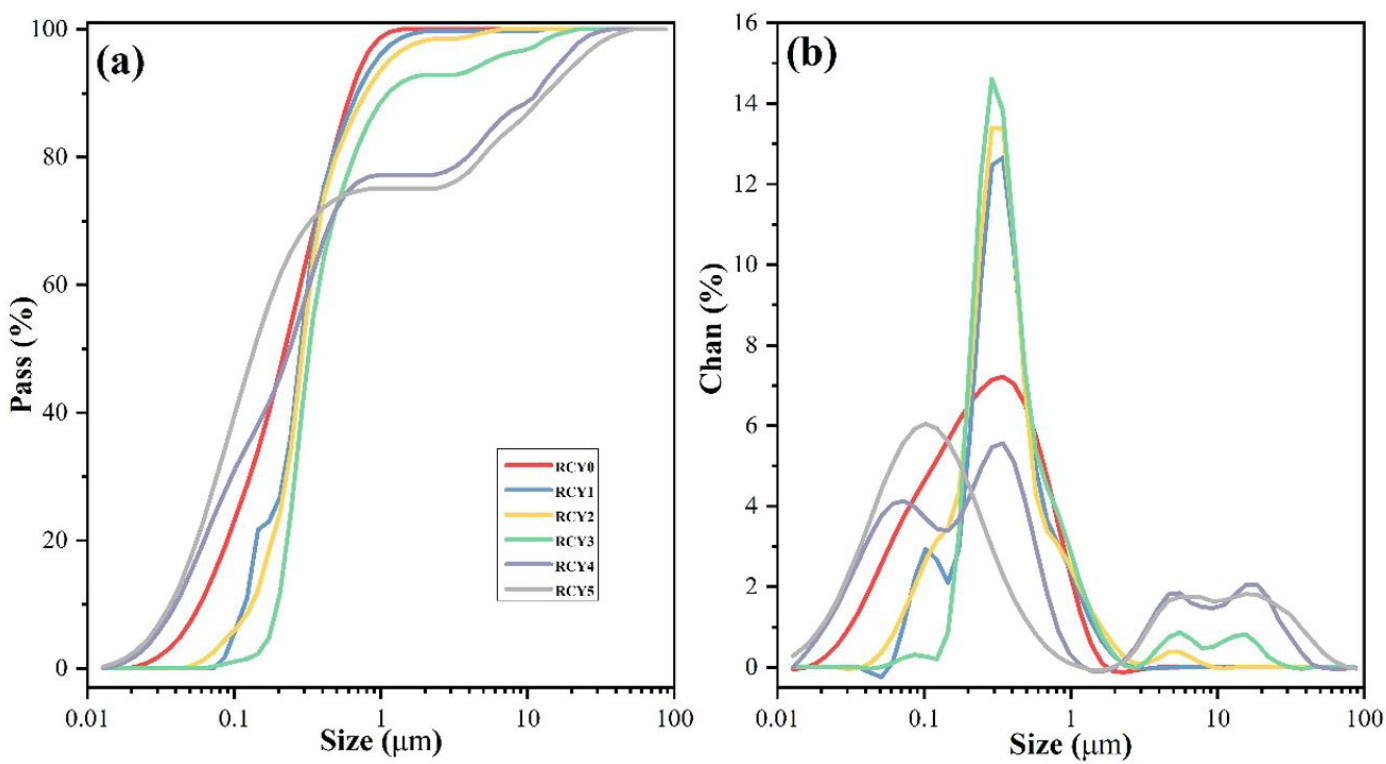

Figure 1. The particle size distribution (PSD) profile showing $\%$ channel as indicative of mean variations (a) PSD distribution of actual roasted chickpea powder dispersed in skim milk before incubation (b). 


\subsection{Rheological characteristics of supplemented yogurt samples}

The storage modulus ( $\left.G^{\prime}\right)$ and loss modulus ( $\left.G^{\prime \prime}\right)$ as functions of frequency and oscillation stress for roasted chickpeas yogurts (RCYs) and control samples have been presented in Figure 2 (a-d), respectively. Rheological properties of both supplemented and control yogurt samples exhibited significant $(p<0.05)$ differences with respect to addition levels of roasted chickpea powder. It was clear from the results of flow curves that all yogurt samples demonstrated commonly found shear-thinning behavior. G' and
G" moduli as a function of frequency and oscillation stress showed weak viscoelastic behavior for all samples regardless of supplementation levels of roasted chickpea powder, which implied improvement in storage stability. All yogurt samples were subjected to stirring prior to modulus measurements because intended consumers are accustomed to stir yogurts prior to consumption. Comparatively, supplemented samples exhibited less degree of shear-thinning as compared to control samples. This can be attributed to the presence of higher amounts of total solids in supplemented yogurts, which caused massive crosslinking bridges between casein micelles and protein particles,
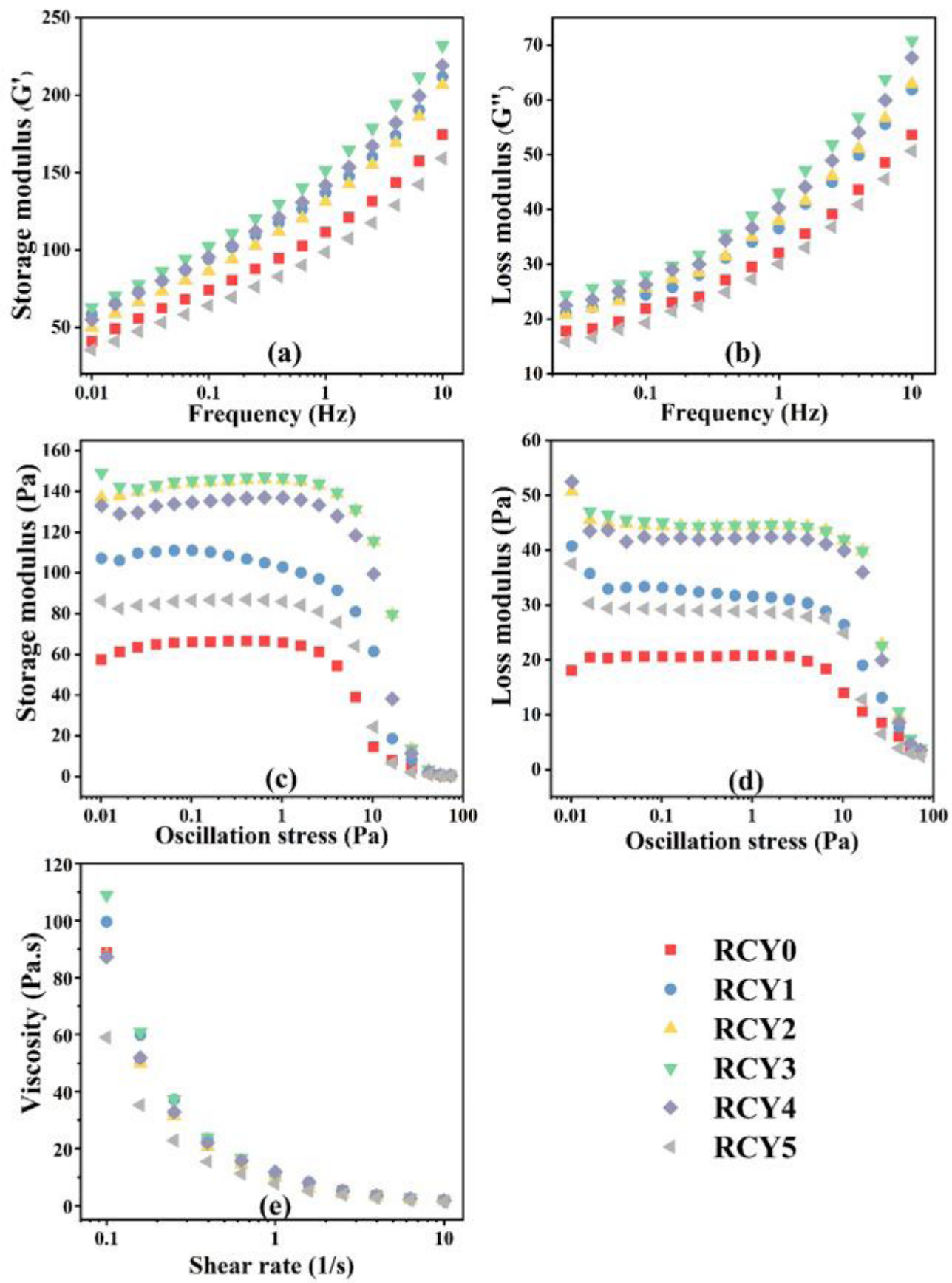

Figure 2. The storage modulus (G, a) and loss modulus (G”, b) as functions of frequency for roasted chickpeas yogurts (RCYs).' The storage modulus (G, c) and loss modulus (G', d) as functions of oscillation stress for roasted chickpeas yogurts (RCYs). Viscosity (Pa.s) versus shear rate $(1 / \mathrm{s})$ relationship of yogurt supplemented with roasted chickpea powders at different concentrations (e). 
which contributes to the higher viscoelasticity of supplemented yogurts.

This also revealed that there was no significant difference in gel-forming structures and involved bonding; however, supplementation of roasted chickpea powder improved the bonding behavior and led to improved structural configurations. Viscoelastic behavior improvement could be ascribed to the fact of increased protein-protein bondings and interactions, which caused less rupture susceptibility by improving the viscoelasticity of yogurt gels. Similar findings have been reported by (Damin et al., 2009) regarding changes in rheological characteristics, the extent of cross-linking, and interactions because of supplementation of skim milk powder, whey protein concentrate and sodium caseinate and structural modification of non-fat stirred yogurts. Supplementation allows incremental rises in total solids, and rheological properties are strongly dependent on the type and amount of proteins in supplemented yogurts. Moreover, increased total solids and protein contents have been linked with increasing tendencies of G' and G" and consequently decreasing

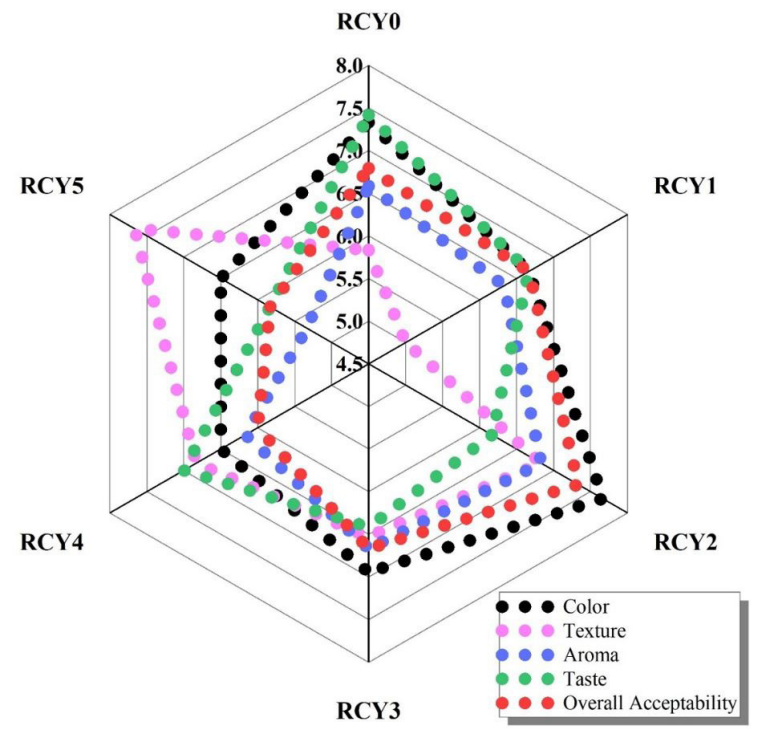

Figure 3. Spider chart of sensory scores of roasted chickpea yogurt (RCYs) based on color, texture, aroma, taste and overall acceptability. tendency of deformation and structural disruption of yogurt gels. Therefore, it could be inferred that supplementation as a prominent factor may lead to structural alterations in gels and hence may exert significant influence on functional and rheological properties, including viscoelasticity and water absorption capacity (Zare et al., 2011). The results viscosity of supplemented and control samples are demonstrated in Figure 2d. Rheology exhibits particular significance for food product characterization, and rheological properties are dependent on distribution ratios of molecular weights and characteristic molecular weights of specific ingredients found in the developed product. Among all supplemented samples, RCY4 and RCY5 showed improved gel structures and viscosity profile as compared to control. Viscosity usually denotes the measure of the inherent friction caused by the testing fluid (Mezger, 2014). The viscosity showed a gradual decline with corresponding rises in shear rate. Viscosity showed a decreasing tendency with corresponding increases in shear rate and exhibited the shear-thinning behavior, which is also referred to as dilatancy. This dilatancy is usually observed in the case of food mixtures including yogurt gels as well.

\subsection{Effects on sensory properties of supplemented yogurt samples}

All control and supplemented yogurt samples were evaluated by sensory analysis, and results are demonstrated in the form of a radar graph shown in Figure 3. In the case of RCY1, all sensory attributes showed resemblance to those of control except texture. The texture score for RCY2 was relatively low, and an increasing tendency was observed in texture with corresponding rises in roasted chickpea powder. RCY5 showed the maximum texture score among all supplemented samples. Changes in the colors of yogurt after the addition of different amounts of RC powders are shown in Figure 4. Color also showed rises in a brownish-yellow tinge with an increase in roasted chickpea powder (Figure 4). RCY5 exhibited the maximum score for color attribute. Aroma showed invariably non-significant changes in all supplemented samples as compared to control. The taste was also influenced by supplementation, and the most desirable taste attribute was found for RCY3, followed by RCY4. The maximum overall acceptability score was exhibited by RCY3, followed by RCY4 and RCY5, respectively. Similar findings have been reported by Zare et al. (2011) for yogurt samples supplemented

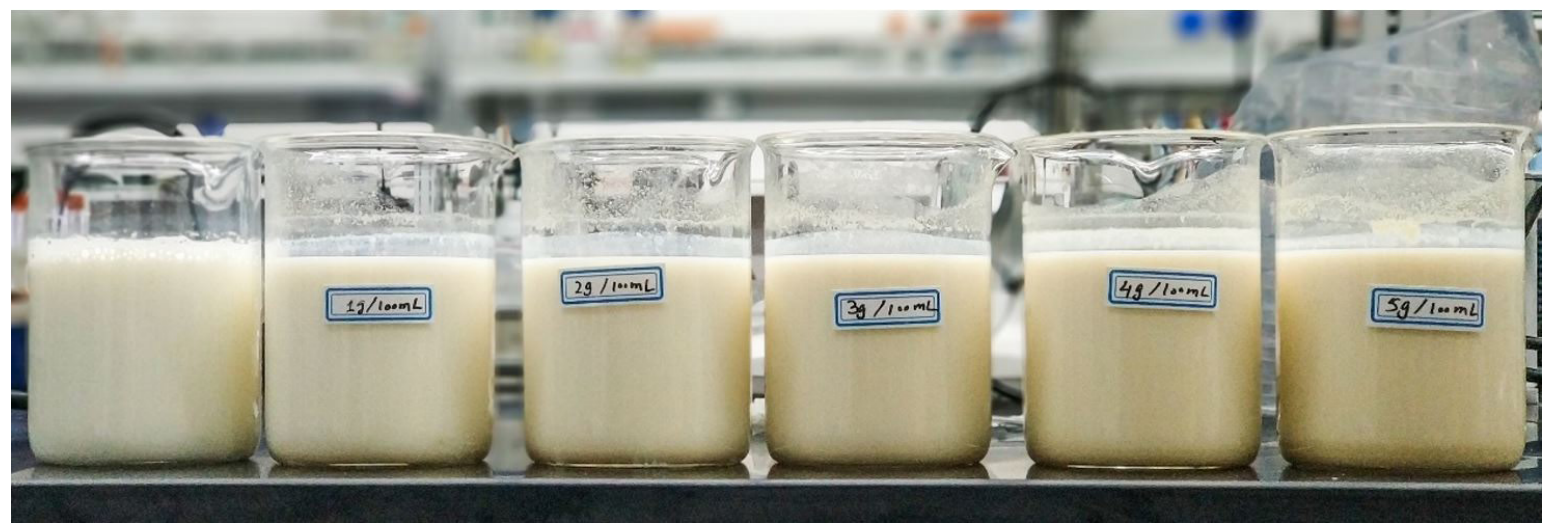

Figure 4. Changes in the colors of yogurt after the addition of different amounts of roasted chickpea powders. 
by lentil, and $2 \%$ supplemented samples showed comparable sensory attributes to those of control samples. In another study by Amerinasab et al. (2015), the yogurts supplemented with date liquid sugar were found to have better sensory properties as compared to the control yogurt.

\section{Conclusions}

In this paper, effects of ball-milled roasted chickpea (RC) powder on yogurt physiochemical, rheological, and sensorial properties were investigated. It was revealed that the addition of powder caused a gradual decline in $\mathrm{pH}$ values of pre-inoculated samples with corresponding increases in powder concentration from 1 to $5 \mathrm{~g} / 100 \mathrm{~mL}$. However, the RCY5 sample showed $\mathrm{pH}$ values similar to RCY0, which revealed that the addition of roasted chickpea powder did not cause any significant change in $\mathrm{pH}$ of yogurt samples as compared to control during the storage period of 1 week. Furthermore, slight increases in lightness and yellowness as compared to control, which can be attributed to the presence of fiber, proteins, and starches in inherent compositions of ball-milled roasted chickpea powder. Significantly higher firmness levels in the range of 59.39-78.56 g were found in RCY3 and RCY5 samples. RCY3 showed the highest consistency value ( $1480.214 \mathrm{~g} / \mathrm{s})$ as compared to that observed for control samples $(1256.87 \mathrm{~g} / \mathrm{s})$. Overall, the syneresis was significantly higher $(p<0.05)$ in control samples as compared to supplemented samples. The addition levels of more than $3 \%$ RC led to improved physicochemical, rheological, and sensory characteristics, Whereas RCY3 showed dispersive patterns similar to that of RCY5. Comparatively, supplemented samples showed less degree of shear-thinning as compared to control samples. Moreover, increased total solids and protein contents have been linked with increasing tendencies of G' and G' and consequently decreasing tendency of deformation and structural disruption of yogurt gels. RCY5 showed the maximum texture score among all supplemented samples and improved sensory attributes as compared to those of control samples.

\section{References}

Amerinasab, A., Labbafi, M., Mousavi, M., \& Khodaiyan, F. (2015). Development of a novel yoghurt based on date liquid sugar: physicochemical and sensory characterization. Journal of Food Science and Technology, 52(10), 6583-6590. http://dx.doi.org/10.1007/ s13197-015-1716-4. PMid:26396404.

Arslaner, A. (2020). The effects of adding garlic (Allium sativum L.) on the volatile composition and quality properties of yogurt. Food Science and Technology, 40(Suppl 2), 582-591. http://dx.doi. org/10.1590/fst.31019.

Barkallah, M., Dammak, M., Louati, I., Hentati, F., Hadrich, B., Mechichi, T., Ayadi, M. A., Fendri, I., Attia, H., \& Abdelkafi, S. (2017). Effect of Spirulina platensis fortification on physicochemical, textural, antioxidant and sensory properties of yogurt during fermentation and storage. LWT, 84, 323-330. http://dx.doi.org/10.1016/j.lwt.2017.05.071.

Barros, R. F. D., Torres, F. R., Silva, P. H. F. D., Stringheta, P. C., Pereira, J. P. F., Paula, J. C. J. D., Cutrim, C. S., \& Cortez, M. A. S. (2020). Lutein as a functional ingredient in sheep milk yogurt: development, characterization and extraction recovery. Food Science and Technology, 40(Suppl. 2), 683-690. http://dx.doi.org/10.1590/fst.36019.
Bosnea, L. A., Kopsahelis, N., Kokkali, V., Terpou, A., \& Kanellaki, M. (2017). Production of a novel probiotic yogurt by incorporation of L. casei enriched fresh apple pieces, dried raisins and wheat grains. Food and Bioproducts Processing, 102, 62-71. http://dx.doi. org/10.1016/j.fbp.2016.11.010.

Ciron, C. I. E., Gee, V. L., Kelly, A. L., \& Auty, M. A. E. (2010). Comparison of the effects of high-pressure microfluidization and conventional homogenization of milk on particle size, water retention and texture of non-fat and low-fat yoghurts. International Dairy Journal, 20(5), 314-320. http://dx.doi.org/10.1016/j.idairyj.2009.11.018.

Coskun, F., \& Karabulut Dirican, L. (2019). Effects of pine honey on the physicochemical, microbiological and sensory properties of probiotic yoghurt. Food Science and Technology (Campinas), 39(Suppl. 2), 616-625. http://dx.doi.org/10.1590/fst.24818.

Damin, M. R., Alcântara, M. R., Nunes, A. P., \& Oliveira, M. N. (2009). Effects of milk supplementation with skim milk powder, whey protein concentrate and sodium caseinate on acidification kinetics, rheological properties and structure of nonfat stirred yogurt. Lebensmittel-Wissenschaft + Technologie, 42(10), 1744-1750. http:// dx.doi.org/10.1016/j.lwt.2009.03.019.

Da Silva, D. F., Junior, N. N. T., Gomes, R. G., dos Santos Pozza, M. S., Britten, M., \& Matumoto-Pintro, P. T. (2017). Physical, microbiological and rheological properties of probiotic yogurt supplemented with grape extract. Journal of Food Science and Technology, 54(6), 16081615. http://dx.doi.org/10.1007/s13197-017-2592-x. PMid:28559620.

Jridi, M., Souissi, N., Salem, M. B., Ayadi, M. A., Nasri, M., \& Azabou, S. (2015). Tunisian date (Phoenix dactylifera L.) by-products: Characterization and potential effects on sensory, textural and antioxidant properties of dairy desserts. Food Chemistry, 188, 8-15. http://dx.doi.org/10.1016/j.foodchem.2015.04.107. PMid:26041157.

Kermiche, F., Boulekbache-Makhlouf, L., Félix, M., Harkat-Madouri, L., Remini, H., Madani, K., \& Romero, A. (2018). Effects of the incorporation of cantaloupe pulp in yogurt: Physicochemical, phytochemical and rheological properties. Food Science \& Technology International, 24(7), 585-597. http://dx.doi.org/10.1177/1082013218776701. PMid:29771134.

Mezger, T. G. (2014). The Rheology Handbook, for users of rotational and oscillatory rheometers. Hanover: Vincentz Network GmbH \& Co.

Öztürk, H. İ., Aydın, S., Sözeri, D., Demirci, T., Sert, D., \& Akın, N. (2018). Fortification of set-type yoghurts with Elaeagnus angustifolia L. flours: Effects on physicochemical, textural, and microstructural characteristics. LWT, 90, 620-626. http://dx.doi.org/10.1016/j. lwt.2018.01.012.

Paseephol, T., Small, D. M., \& Sherkat, F. (2008). Rheology and texture of set yogurt as affected by inulin addition. Journal of Texture Studies, 39(6), 617-634. http://dx.doi.org/10.1111/j.1745-4603.2008.00161.x.

Ramadhan, K., \& Foster, T. J. (2018). Effects of ball milling on the structural, thermal, and rheological properties of oat bran protein flour. Journal of Food Engineering, 229, 50-56. http://dx.doi. org/10.1016/j.jfoodeng.2017.10.024.

Raza, H., Ameer, K., Zaaboul, F., Sharif, H. R., Ali, B., Shoaib, M., Akhtar, W., \& Zhang, L. (2019). Effects of ball-milling on physicochemical, thermal and functional properties of extruded chickpea (Cicer arietinum L.) powder. CYTA: Journal of Food, 17(1), 563-573. http:// dx.doi.org/10.1080/19476337.2019.1617352.

Ribeiro, A. D. S., Silva, M. N., Tagliapietra, B. L., Brum, B. D. S. Jr., Ugalde, M. L., \& Richards, N. S. P. D. S. (2019). Development of symbiotic yoghurt and biological evaluation (New Zealand White Rabbits) of its functional properties. Food Science and Technology (Campinas), 39(Suppl. 2), 418-425. http://dx.doi.org/10.1590/fst.20618. 
Sah, B. N. P., Vasiljevic, T., McKechnie, S., \& Donkor, O. N. (2016). Physicochemical, textural and rheological properties of probiotic yogurt fortified with fibre-rich pineapple peel powder during refrigerated storage. Lebensmittel-Wissenschaft + Technologie, 65, 978-986. http://dx.doi.org/10.1016/j.lwt.2015.09.027.

Sarkar, S. (2019). Potentiality of probiotic yoghurt as a functional food-a review. Nutrition \& Food Science, 49(2), 182-202. http:// dx.doi.org/10.1108/NFS-05-2018-0139.

Soltani, M., Hekmat, S., \& Ahmadi, L. (2018). Microbial and sensory evaluation of probiotic yoghurt supplemented with cereal/pseudo-cereal grains and legumes. International Journal of Dairy Technology, 71, 141-148. http://dx.doi.org/10.1111/14710307.12389.

Staffolo, M. D., Bertola, N., Martino, M., \& Bevilacqua, A. (2004). Influence of dietary fiber addition on sensory and rheological properties of yogurt. International Dairy Journal, 14(3), 263-268. http://dx.doi.org/10.1016/j.idairyj.2003.08.004.
Wang, X., Kristo, E., \& LaPointe, G. (2020). Adding apple pomace as a functional ingredient in stirred-type yogurt and yogurt drinks. Food Hydrocolloids, 100, 105453. http://dx.doi.org/10.1016/j. foodhyd.2019.105453.

Zare, F., Boye, J. I., Orsat, V., Champagne, C., \& Simpson, B. K. (2011). Microbial, physical and sensory properties of yogurt supplemented with lentil flour. Food Research International, 44(8), 2482-2488. http://dx.doi.org/10.1016/j.foodres.2011.01.002.

Zare, F., Champagne, C. P., Simpson, B. K., Orsat, V., \& Boye, J. I. (2012). Effect of the addition of pulse ingredients to milk on acid production by probiotic and yoghurt starter cultures. LebensmittelWissenschaft + Technologie, 45(2), 155-160. http://dx.doi.org/10.1016/j. lwt.2011.08.012.

Zhong, L., Fang, Z., Wahlqvist, M. L., Wu, G., Hodgson, J. M., \& Johnson, S. K. (2018). Seed coats of pulses as a food ingredient: Characterization, processing, and applications. Trends in Food Science \& Technology, 80, 35-42. http://dx.doi.org/10.1016/j.tifs.2018.07.021. 